\title{
ROCK2 Polymorphism and Expression Contribute to Increased Susceptibility and Poor Prognosis in Hepatocellular Carcinoma
}

\author{
Lifeng Qin $\mathbb{D}^{1,2}$, Xin Liu ${ }^{3}$, Li'na Lan ${ }^{4}$, Xiaoping Lv ${ }^{5}$ \\ 'Hubei Provincial Key Laboratory of Occurrence and Intervention of Rheumatic Diseases (Hubei Minzu University), Enshi, 445000, Hubei Province, \\ People's Republic of China; ${ }^{2}$ Department of Gastroenterology, Minda Hospital of Hubei Minzu University, Enshi, 445000, Hubei Province, People's \\ Republic of China; ${ }^{3}$ Department of Pathology, Minda Hospital of Hubei Minzu University, Enshi, 445000, Hubei Province, People's Republic of China; \\ ${ }^{4}$ Departments of infectious diseases, The First Affiliated Hospital of Guangxi Medical University, Nanning, 53002I, Guangxi Zhuang Autonomous \\ Region, People's Republic of China; ${ }^{5}$ Departments of Gastroenterology, The First Affiliated Hospital of Guangxi Medical University, Nanning, 53002I, \\ Guangxi Zhuang Autonomous Region, People's Republic of China
}

Correspondence: Lifeng Qin, Email 15071860695@163.com

\begin{abstract}
Aim: To analyze the association between ROCK2 gene polymorphism/expression and susceptibility/prognosis of hepatocellular carcinoma (HCC).

Methods: Peripheral venous blood from 204 hepatocellular carcinoma patients (HCC group), 242 chronic hepatitis B patients (CHB group), 215 liver cirrhosis patients (LC group) and 201 healthy volunteers (normal group) were collected. ROCK2 gene (including the rs9808232 locus) was amplified by PCR and the products were sequenced. Tumor tissues from patients with HCC and liver tissues from CHB, LC and normal groups were collected, and mRNA and protein expression of ROCK2 gene in liver tissues were tested by RT-qPCR and immunofluorescence, respectively.

Results: Compared with the normal group, the mRNA and protein expression levels of ROCK2 in the HCC group increased significantly $(P<0.05)$, but there are no obvious increases in the CHB and LC groups $(P>0.05)$. ROCK2 gene rs9808232 polymorphism was associated with an increased susceptibility of HCC, and genotypes AC and CC may be risk factors for HCC $(P<0.001)$. There was a significant association between the ROCK2 gene rs9808232 polymorphism and the route of metastasis in HCC patients $(P<0.05)$. According to the Kaplan-Meier analysis, the overall survival of patients with AC and CC genotypes of ROCK2 rs9808232 was much shorter than that of patients with AA genotype (median overall survival, 25.5 months vs 16.0 months; $\log$ rank $P=0.006$ ). The overall survival time of patients with high ROCK2 expression is much shorter than that of patients with low ROCK2 expression (median overall survival time, 15.0 months vs 20.5 months; $\log \operatorname{rank} P=0.008$ ). Compared with genotype AA, the ROCK2 protein levels of genotypes AC and CC were distinctly increased in the HCC group, especially genotype CC $(P<0.05)$. Conclusion: ROCK2 gene rs9808232 polymorphism may contribute to its expression in liver tissue, which may increase the susceptibility and poor prognosis of HCC.
\end{abstract}

Keywords: ROCK2, hepatocellular carcinoma, single nucleotide polymorphism, susceptibility, prognosis

\section{Introduction}

Hepatocellular carcinoma (HCC), a primary malignant tumor of the liver, mostly occurs on the basis of cirrhosis and chronic hepatitis. ${ }^{1}$ According to statistics, there are about 700,000 new cases each year in the world, of which Chinese patients account for $54 \%{ }^{2,3}$ Due to the insidious onset of liver cancer, it is often found in the middle and late stages, and the high degree of malignancy leads to a very poor prognosis. ${ }^{1}$ Therefore, it is extremely important to study the etiology and pathogenesis of HCC and achieve early diagnosis and treatment.

ROCK2, named Rho-associated coiled-coil containing protein kinase 2, is a downstream gene of RhoA. The human ROCK2 gene is located in zone 4 of the second region of the short arm of chromosome 2 , and the length is about $163 \mathrm{~kb}$. Because the 125592th base on the tenth exon of the gene has an A/C single nucleotide polymorphism, the 431 st amino 
acid of the ROCK2 protein encoded by this gene may appear asparagine (Asn) or Threonine (Thr) (rs9808232). The RhoA/Rock signal transduction pathway participate in various pathophysiological processes in the body. ${ }^{4} \mathrm{~A}$ number of studies ${ }^{5-7}$ have shown that ROCK2 gene plays a key role in the pathogenesis of tumors. Currently, it is generally believed that viral hepatitis, aflatoxin, metabolic factors, long-term drinking and smoking are the causes of liver cancer, but genetic susceptibility (including single nucleotide polymorphism) is the basis of liver cancer.

In this study, PCR and gene sequencing methods were used to detect SNPs in HCC patients and healthy subjects in order to explore the association between the ROCK2 gene rs9808232 polymorphism and susceptibility of HCC in the Chinese Han population, and ROCK2 expressions in liver tissue were analyzed. Because HCC cases generally develop on the basis of liver cirrhosis and chronic hepatitis, patients with liver cirrhosis (LC) and chronic hepatitis B (CHB) were used as controls.

\section{Materials and Methods}

\section{Patients and Controls}

From January 2017 to December 2020, 862 participants including 204 HCC patients (HCC group), 242 CHB patients (CHB group), 215 LC patients (LC group) and 201 healthy volunteers (normal group) were enrolled in the First Affiliated Hospital of Guangxi Medical University. Inclusion criteria: 1) patients who have lived in China for a long time and whose immediate family members of the recent three generations are all Han nationality and have not intermarried with other ethnic groups; 2) the diagnosis meets the relative diagnosis norms and guidelines. ${ }^{8-10}$ Exclusion criteria: 1) Patients with other tumors at the same time; 2) patients with other liver diseases except for chronic hepatitis B, chronic hepatitis C, post-hepatitis cirrhosis, alcoholic liver disease, etc.; 3) patients who are related to each other. Tumor TNM staging is based on the Barcelona Clinic Liver Cancer staging standard. ${ }^{11}$

The clinical characteristics of the HCC group and the control groups are shown in Table 1. In terms of age and gender, the four groups of subjects are well balanced and comparable. The study was reviewed and approved by the Ethics Committee of First Affiliated Hospital of Guangxi Medical University (approval number: 2016-KY-E-045), and each subject signed an informed consent form.

Table I Characteristics of the Study Population

\begin{tabular}{|c|c|c|c|c|}
\hline Characteristics & HCC $(n=204)$ & $\operatorname{LC}(n=2 \mid 5)$ & CHB $(n=242)$ & Normal $(n=20 I)$ \\
\hline Age (years) & $52.3 \pm 13.86$ & $50.5 \pm 15.14$ & $49.8 \pm 13.74$ & $51.5 \pm 14.67$ \\
\hline \multicolumn{5}{|l|}{ Gender (n) } \\
\hline - Male & $152(74.5)$ & $162(75.3)$ & $180(74.4)$ & $145(72.1)$ \\
\hline - Female & $52(25.5)$ & $53(24.7)$ & $62(25.6)$ & $56(27.9)$ \\
\hline \multicolumn{5}{|l|}{ HBV infection (n) } \\
\hline - Yes & 163(79.9) & $149(69.3)$ & $242(100.0)$ & $0(0)$ \\
\hline - No & $4 I(20.1)$ & $66(30.7)$ & $0(0)$ & $20 I(100.0)$ \\
\hline \multicolumn{5}{|l|}{ HCV infection (n) } \\
\hline - Yes & $10(4.9)$ & $9(4.2)$ & $0(0)$ & $0(0)$ \\
\hline - No & 194(95.I) & $206(95.8)$ & $242(100.0)$ & $201(100.0)$ \\
\hline \multicolumn{5}{|l|}{ Alcoholic liver disease (n) } \\
\hline - Yes & $39(19.1)$ & $62(28.8)$ & $0(0)$ & $0(0)$ \\
\hline - No & $165(80.9)$ & I53 (7|.2) & $242(100.0)$ & $201(100.0)$ \\
\hline
\end{tabular}

Note: $\mathrm{n}$ represents the number of subjects.

Abbreviations: HBV, hepatitis B virus; HCV, hepatitis C virus; HCC, hepatocellular carcinoma; LC, liver cirrhosis; CHB, chronic hepatitis B. 


\section{PCR Amplification}

About $5 \mathrm{~mL}$ of venous blood from each subject was drawn with a vacuum blood collection tube and stored in an ultra-low temperature refrigerator at $-80^{\circ} \mathrm{C}$. Sample size used for testing: Normal group 201 cases, CHB group 242 cases, LC group 215 cases, HCC group 204 cases. DNA were extracted from whole blood using Blood Genomic DNA Extraction Kit (Takara Biotechnology Co. Ltd., Dalian, China), and then a micro-nucleic acid protein analyzer was used to detect the concentration and purity of DNA, and qualified samples are stored in the refrigerator at $-20^{\circ} \mathrm{C}$.

By querying the NCBI gene database, PCR primers for ROCK2 gene (including rs9808232 site) were designed, and they were entrusted to Takara Biotechnology Co., Ltd. for synthesis. Upstream primer $\left(5^{\prime} \rightarrow 3^{\prime}\right)$ : GAG AAT AAC TTG AAT AAA ACA GCA CA; downstream primer $\left(5^{\prime} \rightarrow 3^{\prime}\right)$ : TTC TAT CAC TTT TGG CAC TC. The target fragment length is $388 \mathrm{bp}$. Configured with $30 \mu \mathrm{L}$ PCR system: $10 \times$ buffer $3 \mu \mathrm{L}, 25 \mathrm{mM} \mathrm{MgCL} 21.8 \mu \mathrm{L}, 10 \mathrm{mM}$ dNTPs $0.6 \mu \mathrm{L}$, upstream primer and downstream primer each $10 \mathrm{pmol}$, Taq DNA polymerase $1 \mathrm{U}$, DNA template $50 \mathrm{ng}$, and finally used $\mathrm{ddH}_{2}$ $\mathrm{O}$ make up to $30 \mu \mathrm{L}$. PCR reaction conditions: pre-denaturation at $95^{\circ} \mathrm{C}$ for 5 minutes, DNA amplification for 40 cycles (denaturation at $94^{\circ} \mathrm{C}$ for $30 \mathrm{~s}$, annealing at $52^{\circ} \mathrm{C}$ for $30 \mathrm{~s}$, extension at $72^{\circ} \mathrm{C}$ for $40 \mathrm{~s}$ ), and final extension at $72^{\circ} \mathrm{C}$ for 5 minutes. Five microliters of the PCR product was taken on a $2 \%$ agarose gel containing nucleic acid dye for electrophoresis $(120 \mathrm{~V}, 45 \mathrm{~min})$, and an ultraviolet light analyzer was used to identify the target fragment.

\section{Gene Sequencing}

The products of PCR were sequenced by Nanjing GenScript Biotechnology Co., Ltd. The sequencing result was finally compared with the sequence in the GenBank database.

\section{Liver Histopathology}

The cancerous tissues of HCC were obtained by surgery. Liver tissues of CHB, LC and normal groups were obtained by liver biopsy. Sample size used for testing: Normal group 46 cases, CHB group 103 cases, LC group 108 cases, HCC group 164 cases. Each fresh liver tissue was divided into two parts, one part was quickly stored in liquid nitrogen for later PCR and immunofluorescence detection; the other part was fixed with $4 \%$ paraformaldehyde, embedded in paraffin, and sliced with a thickness of $4 \mu \mathrm{m}$. Haematoxylin and eosin (HE) staining was used for histological structure analysis.

\section{Reverse Transcription and Real-Time Quantitative Polymerase Chain Reaction (RT-qPCR)}

RT-qPCR was used to detect the mRNA expression of ROCK2. Total RNA was extracted with an RNA extraction kit from liver tissues. First-strand cDNA was synthesised with $1 \mu \mathrm{g}$ of total RNA, and cDNA sample was thereafter amplified in an ABI Prism 7500 Sequence Detection system (Applied Biosystems, Massachusetts, United States) for 40 cycles $\left(95^{\circ} \mathrm{C}\right.$ for $3 \mathrm{~s}, 60^{\circ} \mathrm{C}$ for $\left.34 \mathrm{~s}\right)$ with specific oligonucleotide primers (Takara, Dalian, China). The target genes were normalized to glyceraldehyde 3-phosphate dehydrogenase $(G A P D H)$ expression, and relative quantification was performed using the $2^{-\triangle \Delta C T}$ method. Each sample was analysed in triplicate. Primer sequences: Forward 5'-GAG AAT AAC TTG AAT AAA ACA GCA CA-3', Reverse 5'- TTC TAT CAC TTT TGG CAC TC -3'.

\section{Immunofluorescence}

Next, immunofluorescence was used to detect the protein expression level of ROCK2 in liver tissues of each group. The liver tissue sections were deparaffinized, hydrated, and soaked in $5 \% \mathrm{H}_{2} \mathrm{O}_{2}$ for $10 \mathrm{~min}$. Next, the slides were transferred to sodium citrate buffer solution for heat-induced antigen retrieval. All antibodies are diluted in antibody diluent. The slices were blocked with rabbit anti-ROCK2 antibody (Abcam, Shanghai, China) and incubated overnight at $4^{\circ} \mathrm{C}$. The negative control slices were incubated with PBS. The sections were incubated with fluorescence labelled secondary antibodies for 1 hour at $37^{\circ} \mathrm{C}$. 3,3'-Diaminobenzidine tetrahydrochloride (DAB) solution was used to observe the immunoreactivity, and then the nucleus was stained with DAPI and sealed. Eventually, the slices were analyzed under an optical microscope, and semi-quantitative evaluation was performed using Image-Pro Plus 6.0 system (Media Cybernetics Inc., Bethesda, MD, USA). ${ }^{12}$ Each slice in each group was randomly selected at least three $200 \times$ field of 
view to take pictures. When taking photos, try to fill the entire field of view with the tissue to ensure that the background light of each photo is consistent. Used Image-Pro Plus 6.0 software to convert green/red fluorescent monochrome photos into black and white images, and then selected the same black as the unified standard for judging the positive of all photos and analyzed each photo to get the integrated optical density (IOD) and the pixel area (AREA). Then, the average optical density value (AO value) is calculated, $\mathrm{AO}=\mathrm{IOD} / \mathrm{AREA}$. The larger the $\mathrm{AO}$ value, this is, the higher expression level of the protein.

\section{Patient Follow-Up}

After diagnosis, clinical follow-up was performed every 3 months for the first 2 years and then every 6 months until the patient died or dropped out. The follow-up content included the patient's symptoms, physical examination, testing of AFP, CT or MRI of upper abdomen. If necessary, liver function, HBV-DNA, or HCV-RNA were tested. When the patients did not come to the hospital on time for follow-up, telephone follow-up was conducted instead. ${ }^{13}$

\section{Statistical Analysis}

The statistical analysis in this study was carried out using SPSS 24.0 statistical software (International Business Machines Corporation, New York). The Hardy-Weinberg genetic balance test was used to judge the genetic balance of SNPs. When $P>0.05$, it indicated that the population genes are genetically balanced, that is, the samples were from the same Mendelian population. The genotype frequency and allele frequency between groups were compared using $\chi^{2}$ test. The Kaplan-Meier method was used to analyze the overall survival time (from diagnosis to the last follow-up or death), and the Log rank test was used for comparison. When $P<0.05$, the difference has statistical significance.

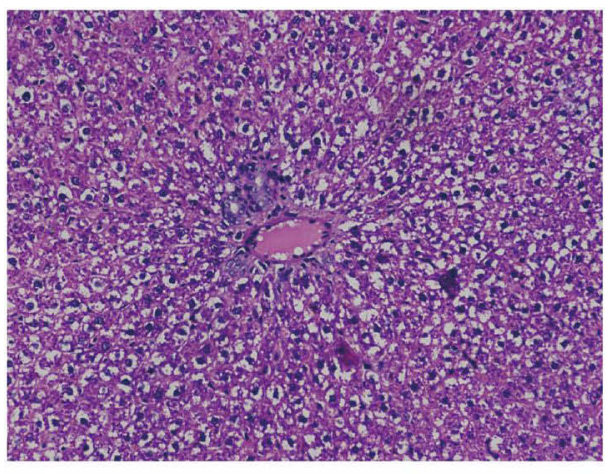

Normal

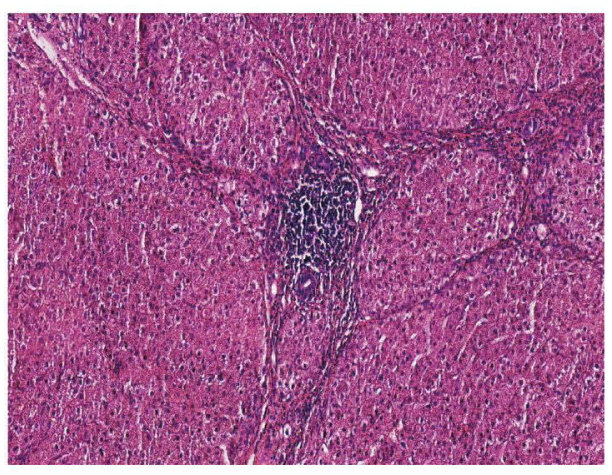

LC

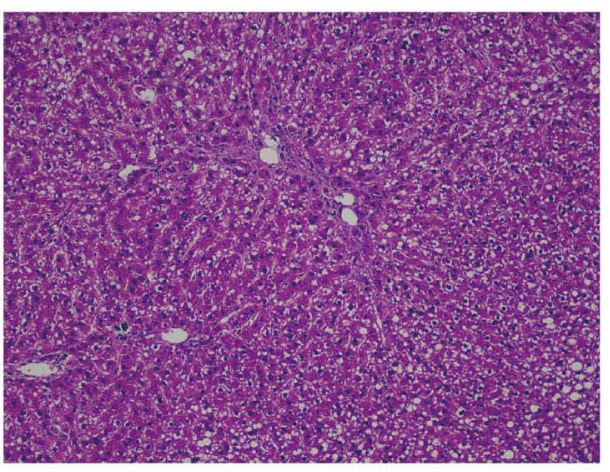

$\mathrm{CHB}$

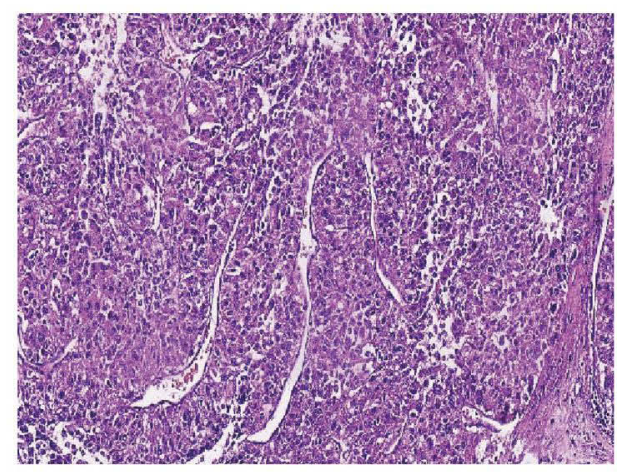

$\mathrm{HCC}$

Figure I HE staining pictures in each group (original magnification, 200x).

Abbreviations: HCC, hepatocellular carcinoma; LC, liver cirrhosis; CHB, chronic hepatitis B. 


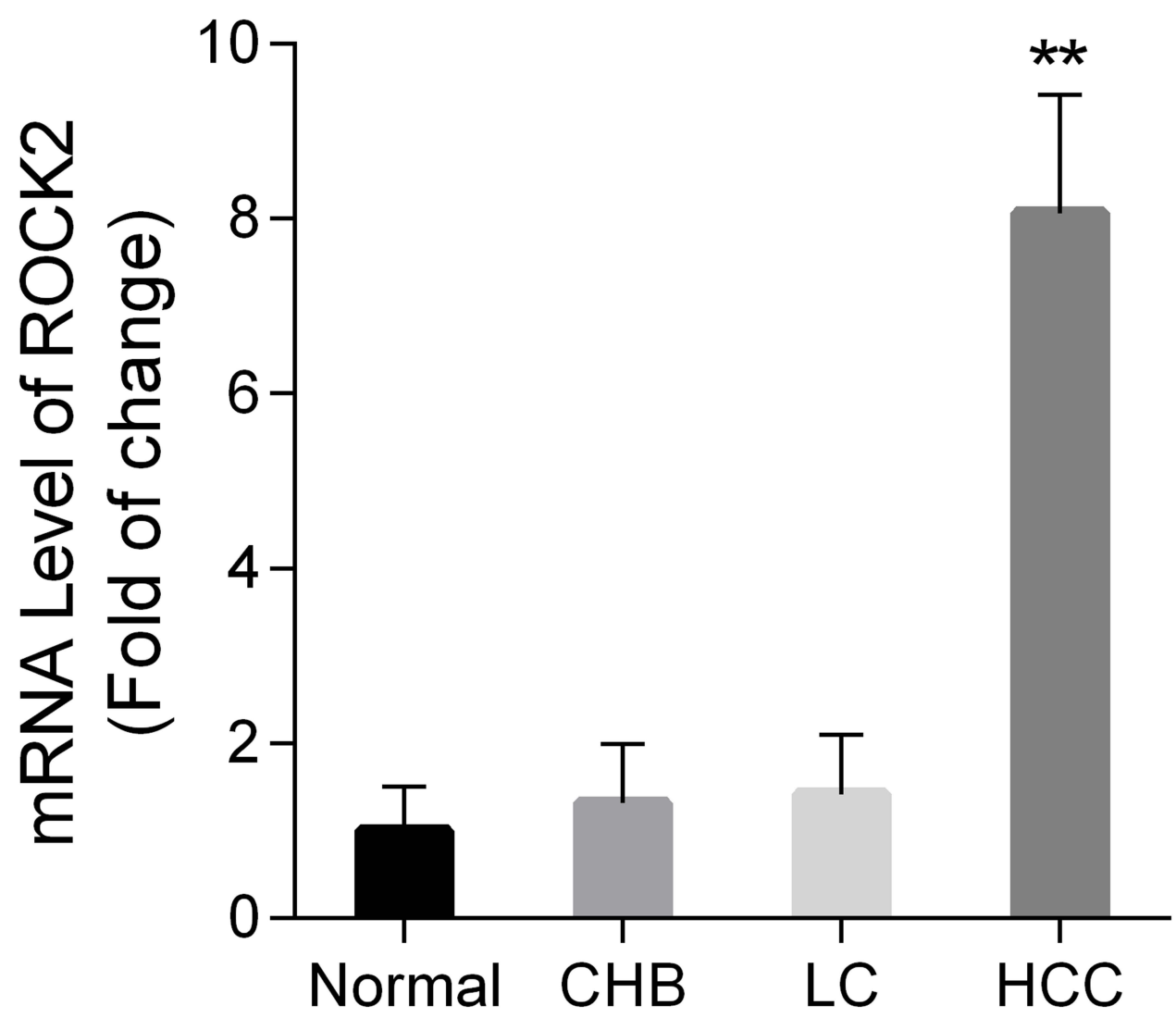

Figure 2 The mRNA expression levels of ROCK2 in liver tissue.

Notes: **P<0.01. Sample size used for testing:Normal group 46 cases, CHB group 103 cases, LC group 108 cases, HCC group 164 cases.

Abbreviations: HCC, hepatocellular carcinoma; LC, liver cirrhosis; CHB, chronic hepatitis B.

\section{Results}

\section{Expression of ROCK2 Gene in HCC and Control Groups}

HE staining pictures of the liver tissue sections in the HCC, LC, CHB and normal groups are shown in Figure 1. As shown in Figures 2 and 3, compared with the normal group, the mRNA and protein expression levels of ROCK2 in the HCC group increased significantly $(P<0.05)$, but there are no obvious increases in the CHB and LC groups compared with the normal group $(P>0.05)$. The results clearly indicate that ROCK2 could take part in pathogenesis of HCC.

\section{Association of ROCK2 Gene rs9808232 Polymorphism with Susceptibility of HCC, $\mathrm{LC}$ and $\mathrm{CHB}$}

Table 1 shows the characteristics of the study population. The sequencing results of all target fragments were consistent with the sequences on the GenBank gene bank. There are three genotypes at rs9808232 locus of ROCK2 gene: AA, AC and CC. The genotype frequency and allele frequency distribution are shown in Table 2. The distribution of genotypes in each group conformed to the law of genetic balance (all $P>0.05$ ), which was representative of the population. The rs9808232 polymorphism of ROCK2 gene was significantly correlated with $\mathrm{HCC}$ susceptibility, suggesting that AC and $\mathrm{CC}$ genotypes may be risk factors for HCC $(P<0.05)$. However, the rs9808232 polymorphism of the ROCK2 gene was not associated with increased susceptibility to CHB and LC $(P>0.05)$. 
A

Normal

$\mathrm{CHB}$

LC

$\mathrm{HCC}$
DAPI
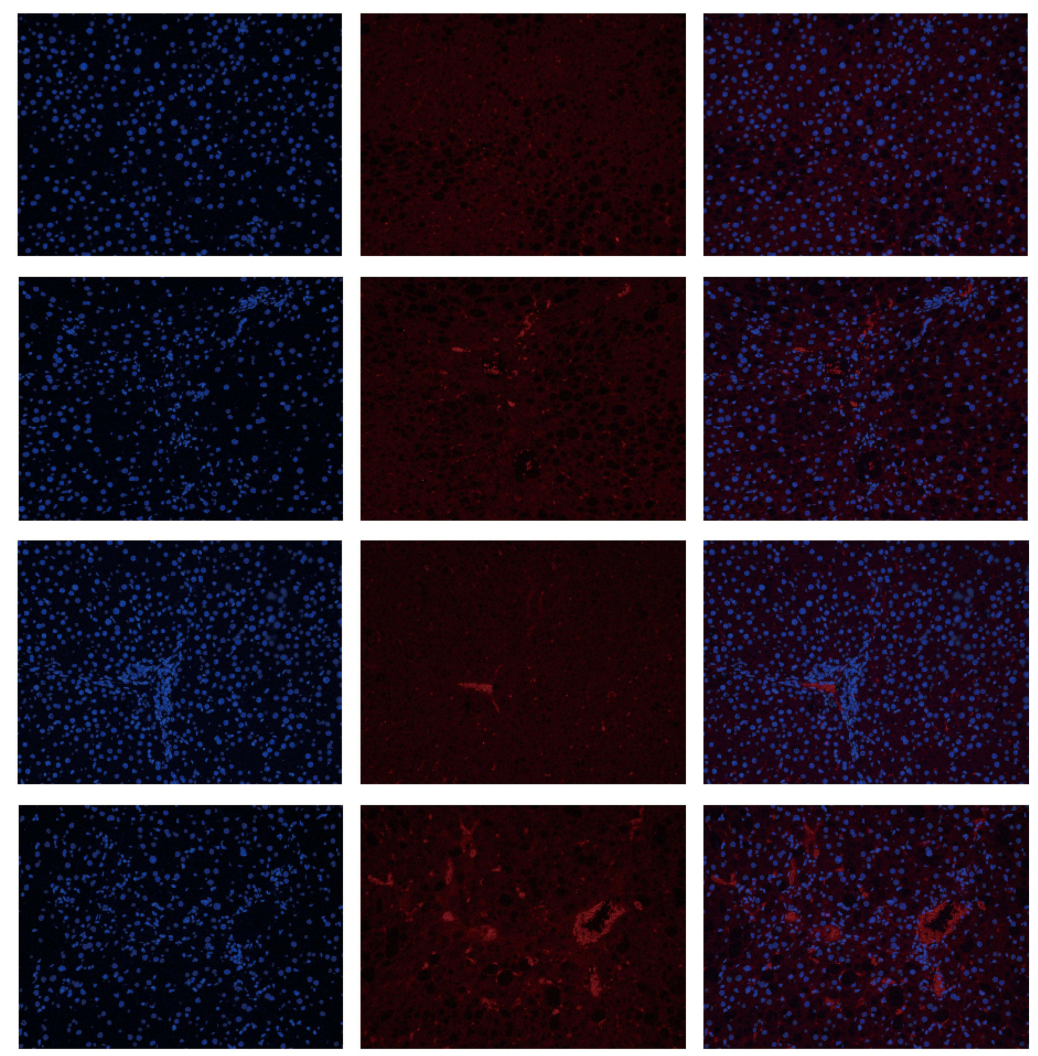

B

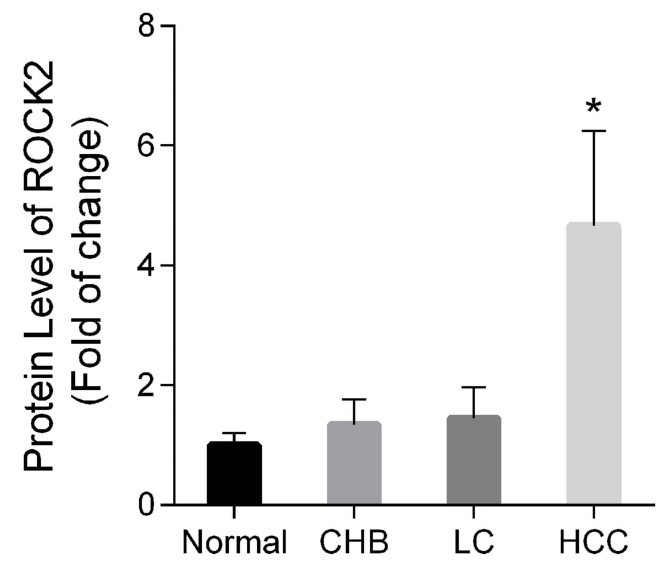

Figure 3 The protein expression levels of ROCK2 in liver tissue. (A) Immunofluorescence staining of ROCK2 (original magnification, 200x). (B) Quantification of ROCK2 staining by digital image analysis.

Notes: $* P<0.05$. Sample size used for testing: Normal group 46 cases, CHB group 103 cases, LC group 108 cases, HCC group 164 cases.

\section{Association of ROCK2 Gene rs9808232 Polymorphism with Clinical Parameters in $\mathrm{HCC}$}

There was a significant association between the ROCK2 gene rs 9808232 polymorphism and the route of metastasis in HCC patients, suggesting that patients with genotypes $\mathrm{AC}$ and $\mathrm{CC}$ are more likely to have extrahepatic metastases $(P<0.05)$. However, there is no obviously association between ROCK2 gene rs9808232 polymorphism and image classification, AFP level or TNM stage in HCC patients $(P>0.05)$ (Table 3). 
Table 2 ROCK2 Gene rs9808232 Polymorphism Genotype and Allele Frequencies in Patients with HCC, $\mathrm{LC}$ and $\mathrm{CHB}$

\begin{tabular}{|c|c|c|c|c|}
\hline Genotype & HCC $(n=204)$ & Normal $(n=20 I)$ & $\chi^{2}$ & $P$ value \\
\hline AA & $40(19.6)$ & $89(44.3)$ & \multirow[t]{3}{*}{30.372} & \multirow[t]{3}{*}{$<0.001$} \\
\hline$A C$ & $113(55.4)$ & $86(42.8)$ & & \\
\hline $\mathrm{CC}$ & $5 I(25.0)$ & $26(12.9)$ & & \\
\hline Allele A & 193(47.3) & $264(65.7)$ & \multirow[t]{2}{*}{27.784} & \multirow[t]{2}{*}{$<0.001$} \\
\hline Allele C & $215(52.7)$ & I38(34.3) & & \\
\hline Genotype & $\operatorname{LC}(n=2 \mid 5)$ & Normal $(n=20 I)$ & $\chi^{2}$ & $P$ value \\
\hline AA & IOI (47.0) & $89(44.3)$ & \multirow[t]{3}{*}{0.457} & \multirow[t]{3}{*}{0.796} \\
\hline$A C$ & $85(39.5)$ & $86(42.8)$ & & \\
\hline $\mathrm{CC}$ & $29(13.5)$ & $26(12.9)$ & & \\
\hline Allele A & $287(66.7)$ & $264(65.7)$ & \multirow[t]{2}{*}{0.107} & \multirow[t]{2}{*}{0.744} \\
\hline Allele C & $143(33.3)$ & $138(34.3)$ & & \\
\hline Genotype & $\mathrm{CHB}(n=242)$ & Normal $(n=20 I)$ & $\chi^{2}$ & $P$ value \\
\hline AA & $96(39.7)$ & $89(44.3)$ & \multirow[t]{3}{*}{1.226} & \multirow[t]{3}{*}{0.542} \\
\hline$A C$ & $108(44.6)$ & $86(42.8)$ & & \\
\hline $\mathrm{CC}$ & $38(15.7)$ & $26(12.9)$ & & \\
\hline Allele A & $300(62.0)$ & $264(65.7)$ & \multirow[t]{2}{*}{1.291} & \multirow[t]{2}{*}{0.256} \\
\hline Allele C & I84 (38.0) & $138(34.3)$ & & \\
\hline
\end{tabular}

Abbreviations: HCC, hepatocellular carcinoma; LC, liver cirrhosis; CHB, chronic hepatitis B.

Table 3 ROCK2 Gene rs9808232 Polymorphism in Relation to Clinical Parameters in Patients with Hepatocellular Carcinoma

\begin{tabular}{|c|c|c|c|c|}
\hline AFP & $>400 n g / m L(n=182)$ & $<400 \mathrm{ng} / \mathrm{mL}(\mathrm{n}=22)$ & $\chi^{2}$ & $P$ value \\
\hline AA & $37(20.3)$ & $3(13.6)$ & 1.852 & 0.396 \\
\hline$A C$ & $102(56.1)$ & II (50.0) & & \\
\hline $\mathrm{CC}$ & $43(23.6)$ & $8(36.4)$ & & \\
\hline Imaging Classification & Lump Type $(n=125)$ & Nodular/Diffuse Types $(n=79)$ & $\chi^{2}$ & $P$ value \\
\hline AA & $19(15.2)$ & $21(26.5)$ & 4.476 & 0.107 \\
\hline AC & $7 I(56.8)$ & $42(53.2)$ & & \\
\hline $\mathrm{CC}$ & $35(28.0)$ & $16(20.3)$ & & \\
\hline TNM Staging & $I / I I(n=8 I)$ & III/IV $(n=123)$ & $\chi^{2}$ & $P$ value \\
\hline AA & 16(19.7) & $24(19.5)$ & 0.007 & 0.996 \\
\hline$A C$ & $45(55.6)$ & $68(55.3)$ & & \\
\hline $\mathrm{CC}$ & $20(24.7)$ & $3 I(25.2)$ & & \\
\hline Transfer Route & Intrahepatic Metastasis $(n=89)$ & Extrahepatic Metastasis $(n=115)$ & $\chi^{2}$ & $P$ value \\
\hline AA & $\mathrm{II}(\mathrm{I} 2.4)$ & $29(25.2)$ & 6.133 & 0.047 \\
\hline AC & $5 I(57.3)$ & $62(53.9)$ & & \\
\hline CC & $27(30.3)$ & $24(20.9)$ & & \\
\hline
\end{tabular}

Abbreviations: OR, odds ratio; AFP, alpha-fetoprotein; TNM staging, tumor node metastasis staging. 


\section{ROCK2 Gene rs9808232 Polymorphism and Prognosis}

Next, survival analysis was performed on patients in the HCC group. At the end of the follow-up, survival information for 164 patients was available (genotype distribution: $37 \mathrm{AA}, 83 \mathrm{AC}$, and $44 \mathrm{CC}$ ). The dropout rate was 19.6\%. The dropout was due to the lack of data. The allele $\mathrm{C}$ of $R O C K 2$ rs9808232 was significantly correlated with the susceptibility of HCC $(P<0.001)$; in addition, the proportions of AC and CC genotypes in the HCC group were 55.4\% and 25.0\%, respectively, which were significantly higher than those in the normal group (42.8\% and $12.9 \%)$. Therefore, AC and $\mathrm{CC}$ genotypes were risk factors for HCC and were analyzed together. According to the Kaplan-Meier analysis, the overall survival of patients with AC and CC genotypes of ROCK2 rs9808232 was much shorter than that of patients with AA genotype (median overall survival, 25.5 months vs 16.0 months; Log rank $P=0.006$ ) (Figure 4). These results show that $\mathrm{AC}$ and $\mathrm{CC}$ genotypes may be indicators of poor prognosis for HCC patients.

\section{ROCK2 Expression Level and Prognosis}

Taking the median expression level of ROCK2 in liver tissue (AO value $=0.006265$ ) as the cut-off point, $164 \mathrm{HCC}$ patients with survival information were divided into high expression group $(n=82)$ and low expression group ( $\mathrm{n}=82$ ). According to the Kaplan-Meier analysis, the overall survival time of patients with high ROCK2 expression is much shorter than that of patients with low ROCK2 expression (median overall survival time, 15.0 months vs 20.5 months; Log rank $P=0.008$; Figure 5). These data indicate that the high expression of ROCK2 may be an indicator of poor prognosis.

\section{Protein Expression Levels of ROCK2 in Patients with HCC Patients with Different Genotypes}

Compared with genotype AA, the ROCK2 protein levels of genotypes AC and CC were distinctly increased in the HCC group, especially genotype $\mathrm{CC}(P<0.05)$ (Figure 6). These results indicate that ROCK2 rs9808232 polymorphism may contribute to its expression in liver tissues.

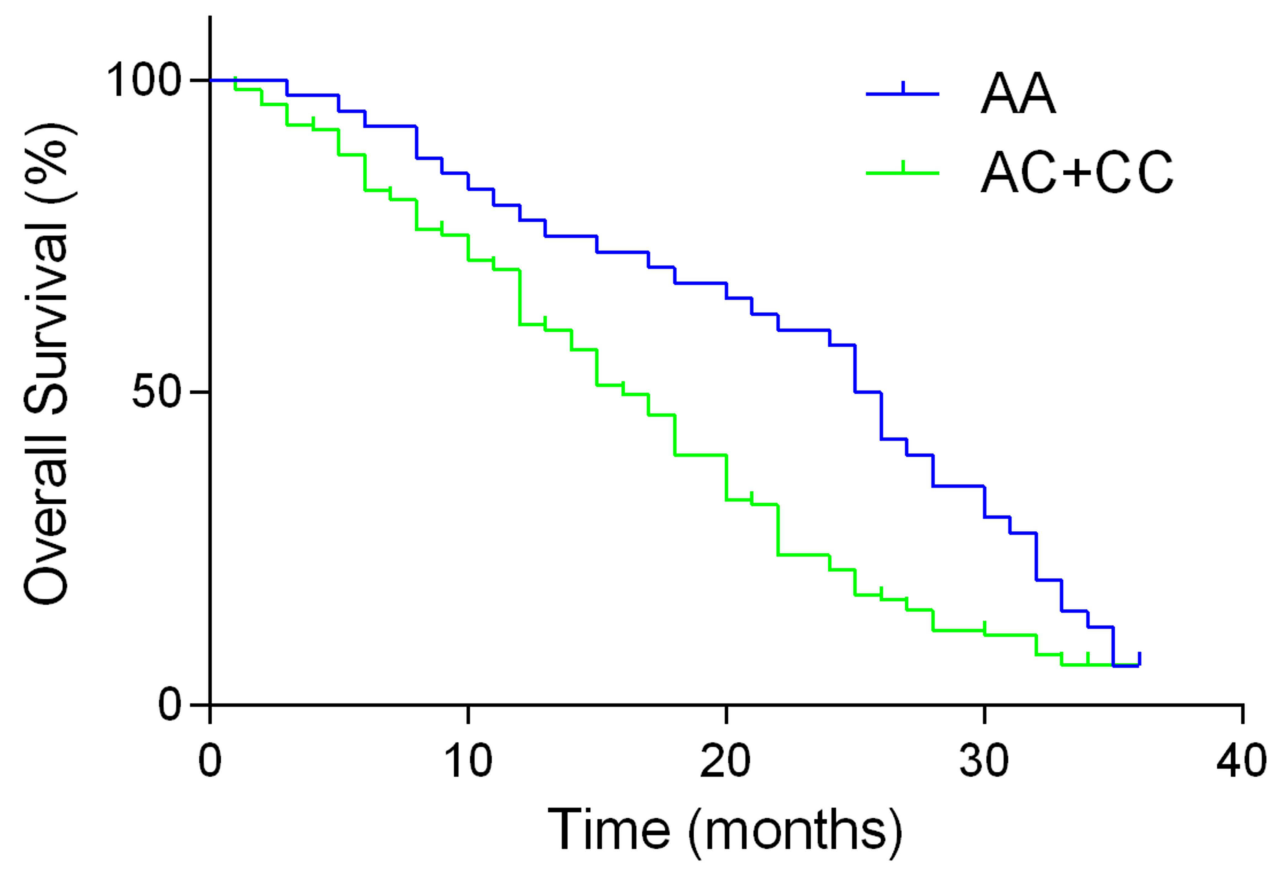

Figure 4 Kaplan-Meier survival curves for patients with different genotypes of ROCK2 rs9808232. Overall survival of patients with the AC and CC genotypes was much shorter compared with those with AA genotype ( $\log$ rank $\mathrm{P}=0.006$ ). 


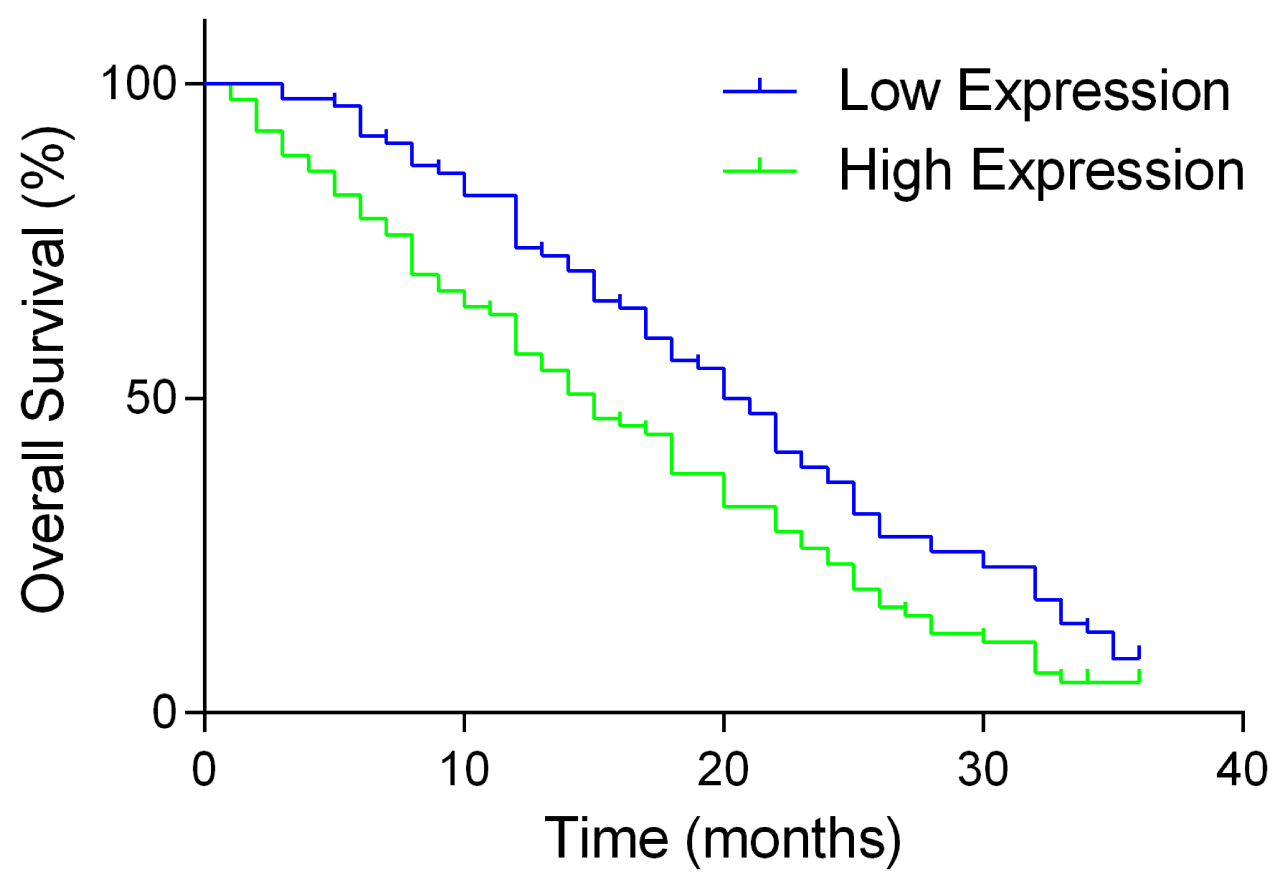

Figure 5 Kaplan-Meier survival curves for patients with low or high expression levels of ROCK2. Overall survival of patients with high expression level of ROCK2 was much shorter compared with those with low expression levels ( $\log$ rank $\mathrm{P}=0.008$ ).

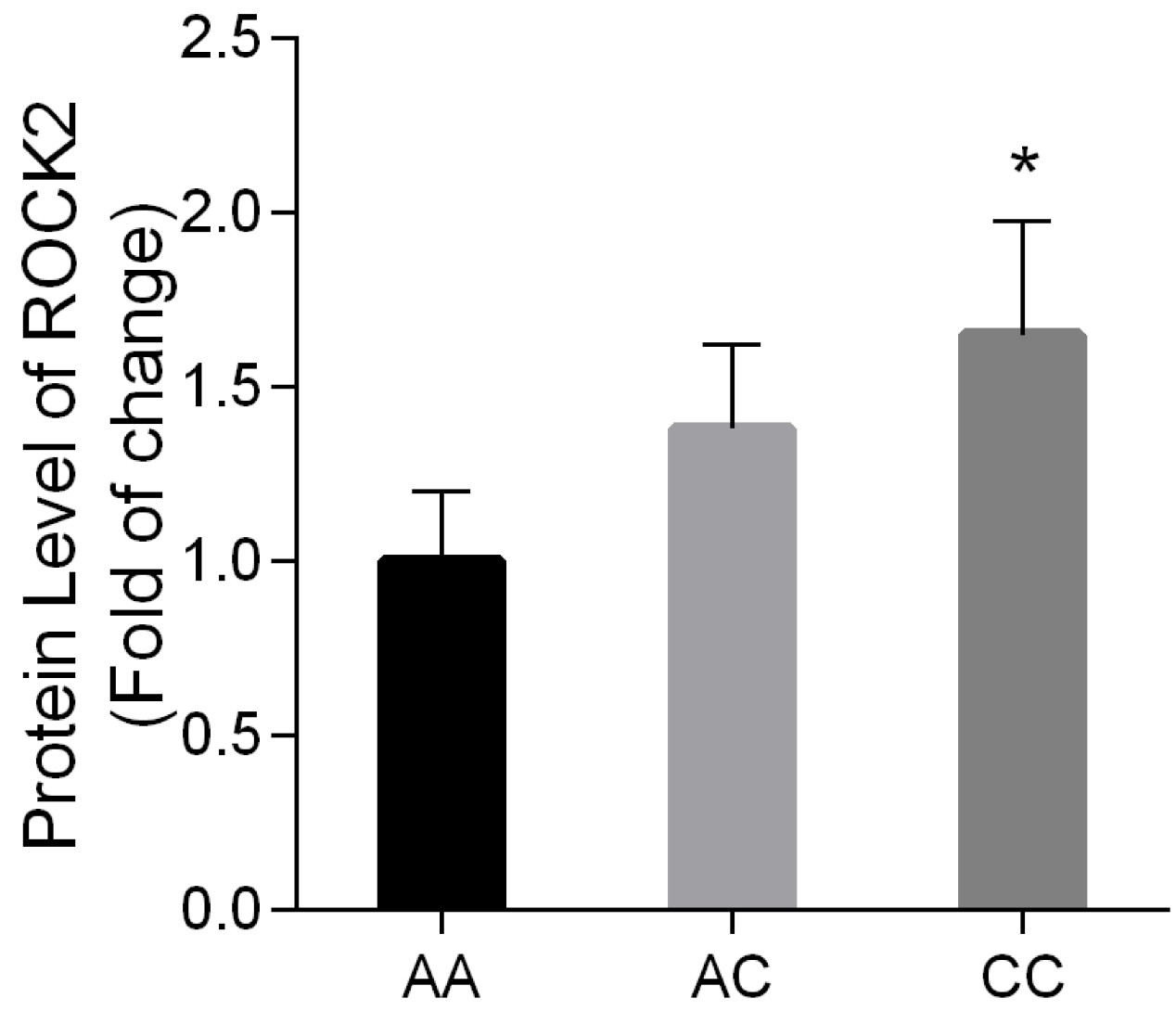

Figure 6 ROCK2 protein level of different genotypes in HCC group. Note: $* P<0.05$ compared with AA genotype. 


\section{Discussion}

ROCK is a kinase that belongs to the serine-threonine kinase family of AGC (PKA/PKG/PKC), which is the main downstream effector of small GTPase RhoA. When the two are combined, it will increase the activity of ROCK kinase. ${ }^{14}$ ROCK is composed of a kinase domain, a coiled-coil region, and a pleckstrin homology (PH) domain. Without RhoAGTP binding to it, it will reduce the kinase activity of ROCKs through self-inhibitory intramolecular folding. ${ }^{15}$ The molecular weight of ROCK is about $160 \mathrm{kDa}$, including two subtypes of ROCK1 and ROCK2. ROCK2 plays a central role in regulating cytoskeleton reorganization and cell shape movement, and is widely involved in cell contraction, adhesion, migration, proliferation and apoptosis. ${ }^{16}$

More and more studies ${ }^{17-22}$ have confirmed that ROCK2 can play an important role in the occurrence and development of tumors by regulating many cell functions, such as tumorigenicity, tumor growth, metastasis, angiogenesis, and tumor cell apoptosis or survival and chemical resistance. Our findings confirm that ROCK2 is involved in the pathogenesis of HCC, and high expression of ROCK2 may be an indicator of poor prognosis. ROCK2 is overexpressed in hepatocellular carcinoma, which is related to more aggressive biological behaviors; moreover, ROCK2 plays an important role in regulating cytoskeletal events and contributes to the invasion of $\mathrm{HCC} .{ }^{23}$ Huang et al ${ }^{24}$ showed that ROCK2 can promote the invasion and metastasis of liver cancer by modifying the ubiquitination and degradation of MMP2 in liver cancer cells. In vitro studies ${ }^{25}$ have also shown that when ultraviolet rays induce DNA damage in liver cancer cells, Rock 2 can protect the survival of liver cancer cells by down-regulating the level of Cdc25A. Therefore, it is believed that Rock2 may be a therapeutic target that determines gene expression regulation in liver cancer cells. Du et $\mathrm{al}^{26}$ showed that ROCK2 can promote ubiquitin-mediated degradation of MKP1 by activating ERK1/2, thereby promoting the invasion and metastasis of HCC. In liver cancer tissues and liver cancer cell lines, miR-185-5p can inhibit HCC cell metastasis by down-regulating ROCK2; The miR-185/ROCK2 axis may be a target to improve the therapeutic effect of HCC and increase the survival rate. ${ }^{27}$ Thus, ROCK2 played an important role in the pathogenesis of HCC.

The high incidence of HCC in China may be related to the high rate of hepatitis B virus infection in the Chinese population, but genetic susceptibility is the basis for liver cancer. A large number of studies ${ }^{28}$ have shown that individual heredity is a key factor that directly affects the occurrence and development of liver cancer; among genetic factors, single nucleotide polymorphisms located in the promoter region or coding region that determine the regulation of gene expression are of great significance. The 429-1131th amino acid residues of ROCK2 protein constitute the coiled-coil region, of which the 979-1047th amino acid may be the region where RhoA molecules bind, and the rs9808232 site polymorphism is located at the beginning of this region. ${ }^{29}$ Therefore, the ROCK2 gene rs 9808232 polymorphism may directly affect the biological function of the ROCK2 protein. Previous studies ${ }^{30-32}$ found that the ROCK2 gene single nucleotide polymorphism is related to the pathogenesis of breast cancer, colorectal cancer, lymphoma and other malignant tumors. However, we have not found a correlation study between ROCK2 gene polymorphism and hepatocellular carcinoma through searching multiple Chinese and English databases. Therefore, this study is innovative. The results of this study indicate that ROCK2 gene rs9808232 polymorphism is related to the susceptibility of HCC, and genotypes $\mathrm{AC}$ and $\mathrm{CC}$ leads to an increased risk. In addition, we also found that ROCK2 gene rs 9808232 polymorphism is related to the metastasis and poor prognosis of HCC, and patients with genotypes AC and CC are more likely to have extrahepatic metastasis and poor prognosis. The high expression of ROCK2 may be an indicator of poor prognosis, and ROCK2 rs9808232 polymorphism may contribute to its expression in liver tissues. So far, due to the lack of similar studies, our research results cannot be compared horizontally.

In conclusion, the high expression of ROCK2 may be an indicator of poor prognosis. ROCK2 gene rs 9808232 polymorphism may contribute to its expression in liver tissue, which may increase the susceptibility of HCC and poor prognosis. However, our research results have yet to be further verified by more and larger sample studies.

\section{Ethics Approval and Consent to Participate}

This study was conducted in accordance with the declaration of Helsinki. This study was conducted with approval from the Ethics Committee of The First Affiliated Hospital of Guangxi Medical University (2016-KY-E-045). A written informed consent was obtained from all participants. 


\section{Funding}

This work was funded by the Hubei Provincial Key Laboratory of Occurrence and Intervention of Rheumatic Diseases (Hubei Minzu University) (No.PT022106) and Doctoral Research Start-up Fund of Minda Hospital of Hubei Minzu University (No.0559).

\section{Disclosure}

The authors declared no potential conflicts of interest with respect to the research, authorship, and/or publication of this article.

\section{References}

1. Kulik L, El-Serag H. Epidemiology and management of hepatocellular carcinoma. Gastroenterology. 2019;156(2):477-491. doi:10.1053/j. gastro.2018.08.065

2. Chen W, Zheng R, Baade PD, et al. Cancer statistics in China, 2015. Ca Cancer J Clin. 2016;66(2):115-132. doi:10.3322/caac.21338

3. Siegel RL, Miller KD, Jemal A. Cancer statistics, 2020. CA Cancer J Clin. 2020;70(1):7-30. doi:10.3322/caac.21590

4. Liu J, Liu M. Research progress on relevant diseases of RhoA/ROCK signaling pathway. J Hainan Med Coll. 2019;25(06):78-82. doi:10.13210/j. cnki.jhmu.20190129.002

5. Hua Y, Wang K, He J, et al. Overexpression of rho-associated coiled-coil containing protein kinase 2 is correlated with clinical progression and poor prognosis in breast cancer. Med Sci Mon. 2018;24:4776-4781. doi:10.12659/MSM.908507

6. Luo J, Lou Z, Zheng J. Targeted regulation by ROCK2 on bladder carcinoma via Wnt signaling under hypoxia. Cancer Biomark. 2019;24 (1):109-116. doi:10.3233/CBM-181949

7. Pranatharthi A, Thomas P, Udayashankar AH, Bhavani C, Srivastava S. RhoC regulates radioresistance via crosstalk of ROCK2 with the DNA repair machinery in cervical cancer. $J$ Exp Clin Cancer Res. 2019;38(1):392. doi:10.1186/s13046-019-1385-7

8. Zhou J, Sun H, Wang Z, Cong W, Fan J. Guidelines for the diagnosis and treatment of hepatocellular carcinoma (2019 edition). Liver Cancer. 2020;9(6):682-720. doi:10.1159/000509424

9. Fukui H, Saito H, Ueno Y, et al. Evidence-based clinical practice guidelines for liver cirrhosis 2015. J Gastroenterol. 2016;51(7):629-650. doi:10.1007/s00535-016-1216-y

10. Hou J, Wang G, Wang F, et al. Guideline of prevention and treatment for chronic hepatitis B (2015 update). J Clin Transl Hepatol. 2017;5 (4):297-318. doi:10.14218/JCTH.2016.00019

11. Forner A, Reig ME, Lope CRD, Bruix J. Current strategy for staging and treatment: the BCLC update and future prospects. Semin Liver Dis. 2010;30(1):61-74. doi:10.1055/s-0030-1247133

12. Qin L, Qin J, Zhen X, Qian Y, Huang L. Curcumin protects against hepatic stellate cells activation and migration by inhibiting the CXCL12/ CXCR4 biological axis in liver fibrosis: a study in vitro and in vivo. Biomed Pharmacother. 2018;101:599-607. doi:10.1016/j.biopha.2018.02.091

13. Qin L, Qin J, Lv X, Yin C, Zhang J. MIF promoter polymorphism increases peripheral blood expression levels, contributing to increased susceptibility and poor prognosis in hepatocellular carcinoma. Oncol Lett. 2021;22(1):549. doi:10.3892/ol.2021.12810

14. Julian L, Olson MF. Rho-associated coiled-coil containing kinases (ROCK) structure, regulation, and functions. Small GTPases. $2014 ; 5:$ :29846. doi:10.4161/sgtp. 29846

15. Pan P, Shen M, Yu H, Li Y, Hou T. Advances in the development of Rho-associated protein kinase (ROCK) inhibitors. Drug Discov Today. 2013;18 (23-24):1323-1333. doi:10.1016/j.drudis.2013.09.010

16. Pelosi M, Marampon F, Zani BM, Prudente S, Rosenthal N. ROCK2 and its alternatively spliced isoform ROCK2m positively control the maturation of the myogenic program. Mol Cell Biol. 2007;27(17):6163-6176. doi:10.1128/MCB.01735-06

17. Chen W, Mao K, Liu Z, Dinh-Xuan A. The role of the RhoA/Rho kinase pathway in angiogenesis and its potential value in prostate cancer (Review). Oncol Lett. 2014;8(5):1907-1911. doi:10.3892/ol.2014.2471

18. Inaba N, Ishizawa S, Kimura M, Fujioka K, Manome Y. Effect of inhibition of the ROCK isoform on RT2 malignant glioma cells. Anticancer Res. 2010;30(9):3509-3514. doi:10.1097/CAD.0b013e32833d19f0

19. Jeong KJ, Park SY, Cho KH, et al. The Rho/ROCK pathway for lysophosphatidic acid-induced proteolytic enzyme expression and ovarian cancer cell invasion. Oncogene. 2012;31(39):4279-4289. doi:10.1038/onc.2011.595

20. Jiang L, Liu X, Kolokythas A, et al. Downregulation of the Rho GTPase signaling pathway is involved in the microRNA-138-mediated inhibition of cell migration and invasion in tongue squamous cell carcinoma. Int J Cancer. 2010;127(3):505-512. doi:10.1002/ijc.25320

21. Kale VP, Hengst JA, Desai DH, et al. A novel selective multikinase inhibitor of ROCK and MRCK effectively blocks cancer cell migration and invasion. Cancer Lett. 2014;354(2):299-310. doi:10.1016/j.canlet.2014.08.032

22. Lane J, Martin TA, Watkins G, Mansel RE, Jiang WG. The expression and prognostic value of ROCK I and ROCK II and their role in human breast cancer. Int J Oncol. 2008;33(3):585-593. doi:10.1002/app.11859

23. Wong CCL, Wong CM, Tung EKK, Man K, Ng IOL. Rho-kinase 2 is frequently overexpressed in hepatocellular carcinoma and involved in tumor invasion. Hepatology. 2010;49(5):1583-1594. doi:10.1002/hep.22836

24. Huang D, Du X, Yuan R, Chen L, Liu T. Rock2 promotes the invasion and metastasis of hepatocellular carcinoma by modifying MMP2 ubiquitination and degradation. Biochem Biophys Res Commun. 2014;453(1):49-56. doi:10.1016/j.bbrc.2014.09.061

25. Li G, Liu T, Yu X, et al. Protective effect and regulation mechanism of Rock2 on ultraviolet-induced DNA damage in liver cancer cells. China Oncol. 2012;22(7):505-509. doi:10.3969/j.issn.1007-3969.2012.07.005 
26. Du Y, Lu S, Ge J, Long D, Zhou W. ROCK2 disturbs MKP1 expression to promote invasion and metastasis in hepatocellular carcinoma. Am $J$ Cancer Res. 2020;10(3):884-896.

27. Niu Y, Tang G. miR-185-5p targets ROCK2 and inhibits cell migration and invasion of hepatocellular carcinoma. Oncol Lett. 2019;17 (6):5087-5093. doi:10.3892/ol.2019.10144

28. Zucman-Rossi J, Villanueva A, Nault JC, Llovet JM. Genetic landscape and biomarkers of hepatocellular carcinoma. Gastroenterology. 2015;149:1226-1239. doi:10.1053/j.gastro.2015.05.061

29. Seasholtz TM, Wessel J, Rao F, et al. Rho kinase polymorphism influences blood pressure and systemic vascular resistance in human twins: role of heredity. Hypertension. 2006;47(5):937-947. doi:10.1161/01.HYP.0000217364.45622.f0

30. Kalender ME, Demiryürek S, Oztuzcu S, et al. Association between the Thr431Asn polymorphism of the ROCK2 gene and risk of developing metastases of breast cancer. Oncol Res. 2010;18(11):583-591. doi:10.3727/096504010X12767359113767

31. Sari I, Berberoglu B, Ozkara E, Oztuzcu S, Demiryurek AT. Role of Rho-kinase gene polymorphisms and protein expressions in colorectal cancer development. Pathobiology. 2013;80(3):138-145. doi:10.1159/000341395

32. Açık DY, Yılmaz M, Sarı İ, Öztuzcu S, Sayıner ZA. Investigation of Rho-kinase expressions and polymorphisms in mantle cell lymphoma patients. Turk J Haematol. 2016;33(2):141-147. doi:10.4274/tjh.2015.0193

\section{Publish your work in this journal}

The International Journal of General Medicine is an international, peer-reviewed open-access journal that focuses on general and internal medicine, pathogenesis, epidemiology, diagnosis, monitoring and treatment protocols. The journal is characterized by the rapid reporting of reviews, original research and clinical studies across all disease areas. The manuscript management system is completely online and includes a very quick and fair peer-review system, which is all easy to use. Visit http://www.dovepress.com/testimonials.php to read real quotes from published authors.

Submit your manuscript here: https://www.dovepress.com/international-journal-of-general-medicine-journal 